\title{
Pancreatic cancer in Canada: Incidence and mortality trends from 1992 to 2005
}

\author{
Robert Flook BSc, Sander Veldhuyzen van Zanten MD PhD FRCPC
}

\begin{abstract}
R Flook, S Veldhuyzen van Zanten. Pancreatic cancer in Canada: Incidence and mortality trends from 1992 to 2005. Can J Gastroenterol 2009;23(8):546-550.
\end{abstract}

BACKGROUND: Pancreatic cancer is the fourth-ranking cause of death among all major malignancies in Canada and has the lowest five-year survival rate.

AIM: To examine incidence and mortality trends of pancreatic cancer in Canada from 1992 to 2005, with particular emphasis on the role of cigarette smoking.

METHODS: Data from Health Canada and Statistics Canada were analyzed for age-adjusted incidence and mortality trends from 1992 to 2005. The future burden of pancreatic cancer in Canada was based on population projections.

RESULTS: The incidence rate of pancreatic cancer for women between 1992 and 2005 remained stable ( 8.49 and 8.48 cases per 100,000, respectively), and there was a decrease in the incidence for men from 11.1 per 100,000 in 1992 to 9.89 per 100,000 in 2005 . This reduction may be the result of a decrease in smoking rates among Canadian men. The mortality rate of this cancer remains high. Approximately $99 \%$ of all pancreatic cancer cases occur in individuals older than 50 years of age. The total number of annual cases of pancreatic cancer in Canada is expected to more than double from 2636 cases in 2006 to 5619 in the year 2031.

CONCLUSION: The incidence of pancreatic cancer in Canada from 1992 to 2005 remained relatively stable, although the incidence decreased somewhat in men, perhaps as a result of a change in smoking behaviour. The total number of cases of pancreatic cancer is expected to more than double by 2031.

Key Words: Incidence; Mortality; Pancreatic neoplasm; Trends

$\Delta$ denocarcinoma of the pancreas is the fourth-ranking Acause of mortality from cancer in Canada and has the poorest five-year survival rate among all major malignancies, with $6 \%$ of individuals surviving five years after diagnosis (1). Globally, this malignancy is responsible for an estimated 220,000 deaths per year, placing it in eighth position among all causes of cancer mortalities $(2,3)$. The incidence of pancreatic cancer is higher in developed countries, suggesting an association with environmental or lifestyle factors $(4,5)$. The incidence of pancreatic cancer in Canada is similar to that of other developed countries such as the United States and those in western Europe, including consistently higher rates in men than in women (4).

A number of nonmodifiable risk factors have been studied including age, sex, race and hereditary factors. Age has been shown to be positively associated with pancreatic cancer (6). More than $80 \%$ of all cases of pancreatic cancer are diagnosed in patients who are between 60 and 80 years of age; the disease

\section{Cancer du pancréas au Canada : Tendances de l'incidence et de la mortalité entre 1992 et 2005}

CONTEXTE : Le cancer du pancréas arrive au quatrième rang des causes de mortalité par cancer important au Canada et il s'accompagne du plus bas taux de survie à cinq ans.

OBJECTIF : Analyser les tendances de l'incidence et de la mortalité par cancer du pancréas au Canada entre 1992 et 2005, avec un accent particulier placé sur le rôle du tabagisme.

MÉTHODE : Les auteurs ont analysé les données de Santé Canada et de Statistique Canada sur les tendances de l'incidence et de la mortalité ajustées selon l'âge pour la période allant de 1992 à 2005. Le fardeau anticipé du cancer du pancréas au Canada se fonde sur des projections de population.

RÉSULTATS : Le taux d'incidence du cancer du pancréas est resté stable chez la femme entre 1992 et 2005 (8,49 et 8,48 cas par 100 000, respectivement) et on a noté une baisse de l'incidence chez l'homme, soit de 11,1 par 100000 en 1992 à 9,89 par 100000 en 2005. Cette réduction peut être attribuable à une diminution du taux de tabagisme chez les hommes canadiens. Le taux de mortalité associé à ce cancer reste élevé. Environ 99 \% de tous les cas de cancer du pancréas s'observent chez des sujets de plus de 50 ans. Le nombre total de cas annuels de cancer du pancréas au Canada devrait plus que doubler, pour passer de 2636 cas en 2006 à 5619 en 2031.

CONCLUSION : L'incidence du cancer du pancréas au Canada est restée relativement stable entre 1992 et 2005, bien que l'incidence ait quelque peu diminué chez les hommes, peut-être par suite d'un changement de leur comportement tabagique. Le nombre total de cas de cancer du pancréas devrait plus que doubler d'ici 2031.

is rarely diagnosed in individuals younger than 45 years of age (6). The incidence in the United States has been reported to be as high as 57 per 100,000 for individuals between 70 and 74 years of age (5), and overall, is more common in men than in women (age-adjusted incidence rate of 13 per 100,000 in men and 9.8 per 100,000 in women) (7). African-Americans had a higher incidence (16.4 per 100,000) (Surveillance, Epidemiology and End Results Program [SEER]) for pancreatic cancer than Caucasians (10.8 per 100,000$)$ (SEER) and other races $(9.8$ per 100,000) (7).

Smoking and family history of pancreatic cancer are two risk factors that have been firmly established (8). Smoking increases the risk of pancreatic cancer twofold and is implicated in the etiology of $20 \%$ to $40 \%$ of all pancreatic cancer cases (5). The evidence suggests that $5 \%$ to $10 \%$ of all cases of pancreatic cancer have a hereditary component (9). Having a family history of pancreatic cancer significantly increases the risk of pancreatic cancer (OR 3.2; 95\% CI 1.8 to 5.6) (9). Individuals who smoked

\footnotetext{
University of Alberta, Edmonton, Alberta

Correspondence: Dr Sander Veldhuyzen van Zanten, Division of Gastroenterology, University of Alberta, Zeidler Ledcor Centre,

130 University Campus, Edmonton, Alberta T6G 2X8. Telephone 780-492-9840, fax 780-492-9865, e-mail vanzanten@ualberta.ca Received for publication October 5, 2008. Accepted January 13, 2009
} 
for more than 20 years and have a family history of pancreatic cancer are at greater risk for pancreatic cancer (OR 5.3; 95\% CI 2.1 to 13.4 ) than nonsmoking individuals with a positive family history (OR 2.2; 95\% CI 1.0 to 7.9) (9). A recent meta-analysis (10) found that a $5 \mathrm{~kg} / \mathrm{m}^{2}$ increase in body mass index increased the risk of pancreatic cancer by $12 \%$. There also appears to be a relationship between diabetes and pancreatic cancer (11). Two studies $(12,13)$, in which diabetes was diagnosed at least five years before pancreatic cancer, reported an elevated risk of 1.98. It has also become clear that new-onset diabetes may be the first manifestation of undiagnosed pancreatic cancer. Acute pancreatitis has been established as a putative risk factor, but the causal mechanism of how acute pancreatitis and diabetes mellitus increase risk remains unclear (8). Coffee, alcohol, red meat, sugar and fat intake, body mass index, gallstones and Helicobacter pylori infection have all been suggested as modifiable risk factors; however, the evidence is inconclusive (8). There is inconclusive evidence regarding possible protective factors such as parity, dietary folate and the use of acetylsalicylic acid or statins (8).

The objective of the present study was to examine trends in the incidence and mortality of pancreatic cancer in Canada from 1992 to 2005, and to project the total number of future cases in Canada, assuming trends in incidence, mortality, fertility and immigration remain constant.

\section{METHODS}

Several Canadian databases were used to examine the trends in incidence and mortality rates of pancreatic cancer. Incidence and mortality data were obtained from the Public Health agency of Canada at 'Cancer Surveillance On-line' (http://dsolsmed.phac-aspc.gc.ca/dsol-smed/cancer/index_e.html). The age-standardized incidence rates from 1992 to 2005 are expressed as the number of cases per 100,000 individuals and are calculated based on the 1991 Canadian census figures. Agestandardized mortality figures from 1992 to 2004 were used because these were the most recent data available.

Five-year survival rates and mortality data were explored using the Statistics Canada publication 'Canadian Cancer Statistics 2008' (www.cancer.ca). Data was presented as a rate per 100,000 based on the 1991 population standard. The reliability of these data is enhanced because Canadian regulations require that all diagnosed cancer cases are reported. Cancer diagnosis data were obtained from the national and provincial cancer registries through provincial pathology laboratories, hospital health record departments, referrals to provincial cancer centres and information listed on death certificates. All major malignancy sites are documented according to the International Classification of Diseases -9 and -10 codes. A network of activities protect data quality and accuracy including automated and manual-edit processes, record linkages and data audits using standards set by the Canadian Cancer Registry and the North American Association of Central Cancer Registries. Completeness of histological confirmation, key data variables and timeliness of reporting were also monitored to help ensure data quality and accuracy. Data regarding Canadian smokers from 1985 to 2006 were obtained from Health Canada's 'Canadian Tobacco Use Monitoring Survey 2006'.

A comprehensive search of Medline (1966 to the present) and EMBASE (1988 to 2008) was performed to search for risk factors for pancreatic cancer. Search terms included "pancreatic cancer", with additional headings including

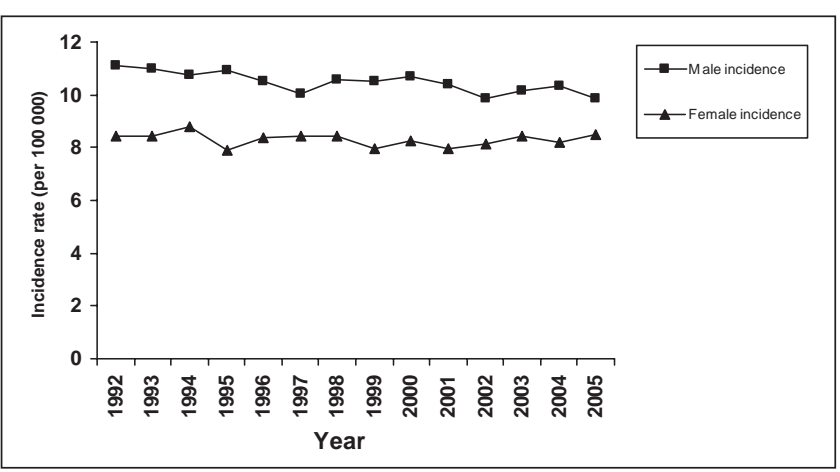

Figure 1) Age-standardized incidence per 100,000 for pancreatic cancer among Canadian men and women from 1992 to 2005. Data adapted from reference 15

“epidemiology”, “mortality”, “incidence”, “trend”, “smoking”, "gender", "age" and "treatment". Other articles were obtained through cross-referencing of relevant articles that were retrieved. Only English language articles were selected.

The projected number of pancreatic cancer cases for 2006, 2026 and 2031 were calculated based on the incidence for Canadians in 2005 (9.24 per 100,000 for men and women combined). The incidence of pancreatic cancer is very low in individuals younger than 50 years of age $(1.18$ per 100,000$)(14,15)$. The projected number of Canadians in each age cohort (50 to 54,55 to 59,60 to 69,70 to 74,75 to 79 and 80 to 84 years of age) for 2006, 2026 and 2031 were calculated using Statistics Canada's population estimates and projections (http://www40. statcan.ca/101/cst01/demo08a.htm). Projections are based on a medium growth-rate scenario using similar fertility rates and immigration rates from previous years, in addition to a moderate increase in life expectancy. Population projections from Statistics Canada were most recently modified in December 2005. There was insufficient information available in the Canadian databases to explore differences in pancreatic cancer epidemiology among different races.

\section{Incidence and mortality}

\section{RESULTS}

Figure 1 shows the age-standardized incidence of pancreatic cancer in men and women from 1992 to 2005. The incidence for men in Canada decreased slightly from 11.1 per 100,000 in 1992 to 9.89 per 100,000 in 2005. This represents a $10 \%$ decrease. In contrast, the incidence for women remained stable between 1992 and 2005, with rates of 8.49 and 8.48 per 100,000 , respectively. There was a small, unexplained drop in the incidence of pancreatic cancer in women in 1995 (7.91 per $100,000)$ that was not observed in men. Overall, the incidence for men was 1.27 times greater than the incidence for women.

Approximately $99 \%$ of all pancreatic cancer cases occur in individuals older than 50 years of age. There is a sharp, nonlinear increase in risk for persons older than 50 years of age. The incidence rate for the 20 to 49 years of age cohort is 1.15 per 100,000 ; 50 to 70 years of age cohort was 25.18 per 100,000 ; and the 75 to 80 years and older age cohort was 76.80 per 100,000 .

There was no observed difference noted over time in the age-specific incidence trends of pancreatic cancer among Canadian men and women between 1992 and 2005. 


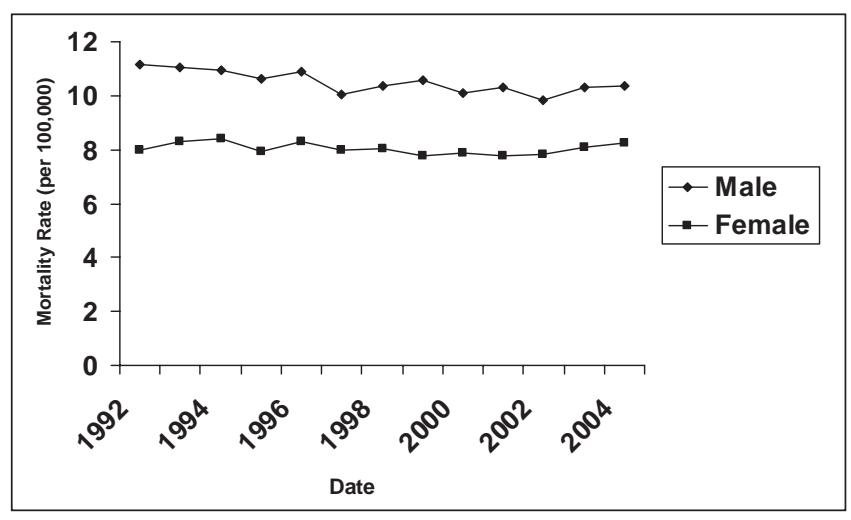

Figure 2) Age-standardized mortality rates per 100,000 in Canada between 1992 and 2004. Data adapted from reference 15

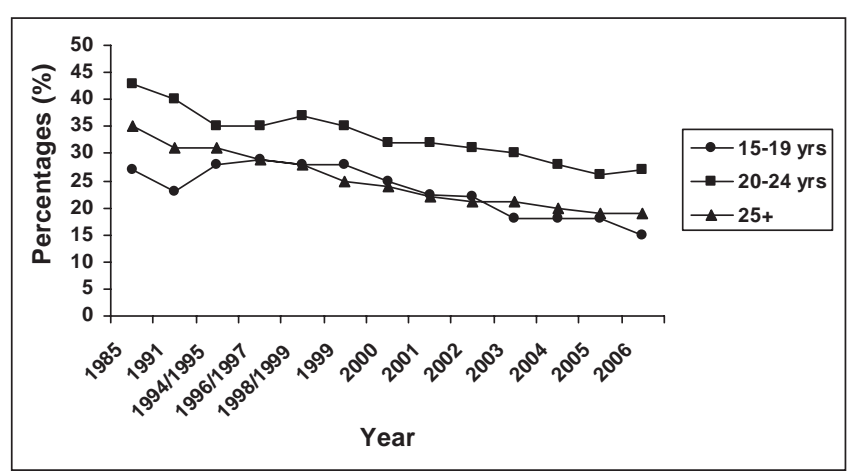

Figure 3) Prevalence of long-term smokers in Canada from 1985 to 2006. yrs Years of age. Data adapted from reference 16

Figure 2 illustrates the age-standardized mortality rates due to pancreatic cancer from 1992 to 2004 among Canadian men and women (15). These mortality rates follow a similar pattern to the incidence data presented in Figure 1. Male mortality rates decreased from 11.18 per 100,000 in 1992 to 10.38 per 100,000 in 2004 , representing a $7 \%$ reduction. Female mortality rates increased from 7.98 per 100,000 in 1992 to 8.23 per 100,000 in 2004 - a $3 \%$ rise in mortality. The mortality rates and the incidence figures are very similar, emphasizing the poor prognosis of this disease in most patients.

The definition used for a current smoker is a person who has smoked at least 100 cigarettes in their lifetime and who smoked at least one cigarette per day for 30 days before the survey was taken (16). The prevalence of current Canadian smokers from 1985 to 2006 is illustrated in Figure 3. There are three age cohorts: 15 to 19,20 to 24 and older than 25 years of age. All three slopes show a decrease in the prevalence of smokers during this time period (16). The percentage of smokers in the 20 to 24 years of age cohort decreased from $43 \%$ in 1985 to $27 \%$ in 2006; the older than 25 years of age cohort decreased from $35 \%$ in 1985 to $19 \%$ in 2006 (17). Since 1990, smoking rates in Canada have undergone a sharp decline (16). Between 1999 and 2002, approximately 700,000 fewer Canadians were smoking, and an estimated 5.9 billion fewer cigarettes were smoked (16). Smoking rates among men have declined at a faster rate than among women, although there are still more male smokers than female smokers (Figure 4). This might be one explanation for the slight decrease in the incidence and mortality of

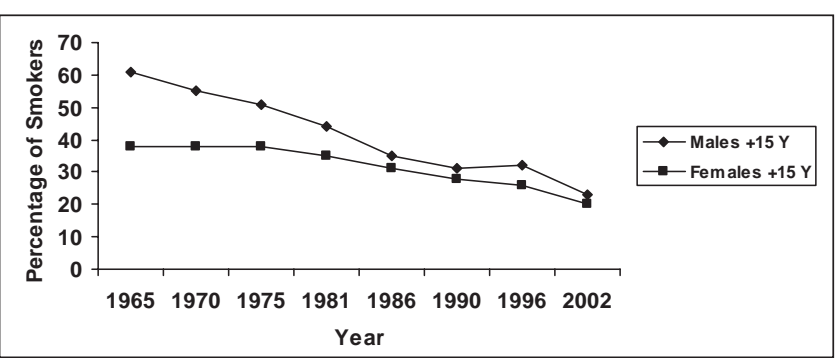

Figure 4) Percentage of Canadian smokers from 1965 to 2002 for individuals older than 15 years $(Y)$ of age. Data adapted from reference 17

pancreatic cancer in men that is not seen in women. The expected benefit of reduced smoking rates in men compared with women is possibly diminished somewhat because the average number of cigarettes smoked by men (20.8 per day) is higher than for women (15.1 per day) (16). Adding to this difficulty, is the finding that the highest number of cigarettes smoked per day is in age cohorts older than 55 years of age for both sexes (16).

The proportion of Canadian residents older than 65 years of age is expected to increase dramatically by 2031. In 2006, Canadians older than 65 years of age accounted for $13.7 \%$ of the total population. By 2031, they are expected to account for $25 \%$ of the population. The increased proportion of aging Canadians over the next 25 years is the result of the 'baby boomer' cohort (born between 1946 and 1965) entering their 'senior years' (18). Table 1 presents the total number of pancreatic cancer cases for Canadian men and women in 2006 and the number of projected cases for five time periods from 2006 to 2031. The projected number of cases are based on a medium growth rate scenario obtained from Statistics Canada and the incidence of pancreatic cancer in 2004 for each specific age cohort (19). The projected total number of cases of pancreatic cancer between 2006 and 2031 increases for all age groups older than 50 years. Between 2006 and 2031, the total number of pancreatic cancer cases is expected to increase by more than twofold, rising from 2636 to 5619 cases per year. Assuming the incidence of pancreatic cancer remains unchanged since 1992, the total number of mortalities is expected to more than double by 2031 due to an aging population.

\section{DISCUSSION}

The major findings from the present study are that the agestandardized pancreatic cancer incidence trend in Canada has decreased by $10 \%$ in men, dropping from 11.1 per 100,000 in 1992 to 9.89 per 100,000 in 2005, while the incidence in women has remained constant at 8.49 per 100,000 in 1992 and 8.48 per 100,000 in 2005 . A recent study (7) found a stable incidence of pancreatic cancer rates in the United States, with 11.3 and 10.9 cases per 100,000 in 1997 and 2001, respectively. Our results are similar to recent trends observed in Sweden (20), where the reduction in incidence has been more pronounced among men than in women, although the overall incidence remained higher among men than women. There has been little change in the average age of diagnosis, with the data showing a sharp nonlinear increase for the 50 to 74 and older than 75 years of age cohorts, confirming that age is a major risk factor for pancreatic cancer. Although there has 
been a slight decrease in the age-standardized mortality rates of $7 \%$ for men (from 11.18 per 100,000 in 1992 to 10.38 per 100,000 in 2004) and a slight increase of $3 \%$ in women (from 7.98 per 100,000 in 1992 to 8.23 in 2004), the overall prognosis of pancreatic cancer remains dismal, with a very low fiveyear survival rate of $6 \%$. Whether the slight decrease in mortality rate in men is the result of earlier detection of pancreatic cancer for a small proportion of cases or to improved surgical techniques is unclear. There is evidence suggesting that small improvements in outcome have been achieved in survival following pancreatic surgery (14). The only curative treatment for pancreatic cancer is curative intent surgery (CIS). A recent United States population-based study documented that only $10.9 \%$ of patients are considered potential candidates for CIS (14).

The population of Canadians older than 65 years of age is projected to increase steadily and will reach $25 \%$ of the total Canadian population by 2031 (18). This increase will have a significant impact on the total number of diagnosed pancreatic cancer cases even though the overall incidence is expected to remain relatively stable because there is only a slight decline in incidence in men. Assuming the trends in incidence for men and women remains constant for individuals 50 to 84 years of age, the total number of cases of pancreatic cancer can be expected to more than double from 2637 cases in 2006 to 5619 cases in 2031 (Table 1). This reiterates that age is an important risk factor for the total burden of pancreatic cancer.

Smoking has been identified as the most significant modifiable risk factor associated with pancreatic cancer $(7,21)$. Smoking doubles the risk of developing pancreatic cancer compared with nonsmokers $(5,21)$. Calculations indicate that cigarette smoking accounts for approximately $20 \%$ to $40 \%$ of all new cases of pancreatic cancer (21). The lag time between starting smoking and developing pancreatic cancer is believed to be approximately two decades $(21,22)$. As shown in Figure 4, the proportion of smokers is higher for men than for women, although the rates for both are declining. It is unclear from these data whether the 1.27 times higher incidence of pancreatic cancer in men is explained by these smoking figures. Fortunately, the prevalence of current smokers in Canada has decreased for all age cohorts during the years from 1985 to 2006 (Figure 3), but more so in men than in women (17). One could speculate that this is the explanation for the observed decrease in age-standardized mortality, which is of greater magnitude among men than in women $(7 \%$ decrease versus a 3\% increase). Given the data, we believe that the observed change in incidence and mortality of pancreatic cancer, which is more pronounced in men than in women, is likely best explained by the changing patterns of smoking in the Canadian population.

Pancreatic cancer has the poorest prognosis of all major malignancies and the lowest five-year survival rate. This remains true despite the recent small improvements seen with CIS and palliative treatment using gemcitabine, other chemotherapy and radiotherapy $(14,23,24)$. Efforts to detect and modify risk factors for the development of pancreatic cancer and improved methods for early detection will need to be pursued (24).

\section{CONCLUSION}

The present study demonstrated that the mortality rate of pancreatic cancer in Canada has remained high, despite a slight

\section{TABLE 1}

Number of cases of pancreatic cancer in Canada from 2006 and projected numbers for five-year intervals ending in 2031

\begin{tabular}{lrrrrrr}
\hline \multirow{2}{*}{$\begin{array}{l}\text { Age group, } \\
\text { years }\end{array}$} & $\mathbf{2 0 0 6}$ & $\mathbf{2 0 1 1}$ & $\mathbf{2 0 1 6}$ & $\mathbf{2 0 2 1}$ & $\mathbf{2 0 2 6}$ & $\mathbf{2 0 3 1}$ \\
\cline { 2 - 7 } & 220 & 247 & 251 & 226 & 225 & 238 \\
$50-54$ & 310 & 384 & 390 & 398 & 359 & 358 \\
$60-64$ & 377 & 484 & 542 & 610 & 623 & 564 \\
$65-69$ & 450 & 555 & 713 & 802 & 905 & 927 \\
$70-74$ & 544 & 590 & 731 & 942 & 1065 & 1208 \\
$75-79$ & 600 & 621 & 680 & 849 & 1102 & 1257 \\
$80-84$ & 509 & 553 & 578 & 642 & 811 & 1063 \\
Total & 2636 & 3398 & 3885 & 4469 & 5092 & 5619 \\
\hline
\end{tabular}

The number of cases were calculated for each age group based on the combined incidence of pancreatic cancer for men and women in 2005 (9.24 per 100,000)

decrease in the incidence for men. The mortality rate remains high because there have been no significant changes regarding earlier detection and, therefore, better chances for successful CIS. The decrease in incidence is more pronounced in men than in women, and is possibly due to a change in smoking behaviour in men. Age is an important risk factor and because of the aging population, the total number of cases of pancreatic cancer is expected to more than double over the next 20 years.

Currently, the only established modifiable risk factor is cigarette smoking. Reducing rates of cigarette smoking is the most promising strategy to prevent pancreatic cancer and the Canadian data are encouraging in that regard. The understanding of other risk factors for pancreatic cancer is limited except for body mass index, which has more recently shown some promise as a modifiable risk factor. Diagnosis of earlystage pancreatic cancer continues to remain challenging. Better understanding of the epidemiology and risk factors will hopefully reveal opportunities for prevention or improvement in the treatment of this disease, which currently has a very poor prognosis.

\section{REFERENCES}

1. Canadian cancer statistics 2008. <http://www.cancer.ca/vgn/images/ portal/cit 86751114/31/21/935505792cw_2008stats_en.pdf.pdf> (Version current at August 10, 2008).

2. Parkin DM, Bray F, Ferlay J, Pisani P. Global cancer statistics 2002. CA Cancer J Clin 2002;55:74-108.

3. Li D, Xie K, Wolff R, Abbruzzese J. Pancreatic cancer. Lancet 2004;363:1049-57.

4. Katanoda K, Dongmei Q. Comparison of time trends in pancreatic cancer incidence (1973-97) in East Asia, Europe and USA, from Cancer Incidence in Five Continents Vol. IV-VIII. Jpn J Clin Oncol 2008;38:165-6.

5. Lowenfels AB, Maisonneuve P. Epidemiology and risk factors for pancreatic cancer. Best Pract Res Clin Gastroenterol 2006;20:197-209.

6. Ghadirian P, Lynch HT, Krewski D. Epidemiology of pancreatic cancer: An overview. Cancer Detect Prev 2003;27:87-93.

7. Shaib YH, Davila JA, El-Serage HB. The epidemiology of pancreatic cancer in the United States: Changes below the surface. Aliment Pharmacol Ther 2006;24:87-94.

8. Hart AR, Kenndy H, Harvey I. Pancreatic cancer: A review of the evidence on causation. Clin Gastroenterol Hepatol 2008;6:275-82.

9. Silverman DT, Schiffman M, Everhart J, et al. Diabetes mellitus, other medical conditions and familiar history of cancer as risk factors for pancreatic cancer. Br J Cancer 1999;80:1830-7. 
10. Larsson SC, Orsini N, Wolk A. Body mass index and pancreatic cancer risk: A meta-analysis of prospective studies. Int J Cancer 2007;120:1993-8

11. Pisani, P. Hyper-insulinaemia and cancer, meta-analyses of epidemiological studies. Arch Physiol Biochem 2008;114:63-70.

12. Gapstur SM, Gann PH, Lowe W, Liu K, Colangelo, Dyer A. Abnormal glucose metabolism and pancreatic cancer mortality. JAMA 2000;283:2552-8

13. Stolzenberg-Solomon RZ, Graubard BI, Chari S, et al. Insulin, glucose, insulin resistance, and pancreatic cancer in male smokers. JAMA 2005;294:2872-8.

14. Shaib YH, Davila J, Naumann C, El-Serage H. The impact of curative intent surgery on the survival of pancreatic cancer patients: A U.S. population-based study. Am J Gastroenterol 2007;107:1377-82.

15. Public Health agency of Canada. Cancer surveillance online. $<$ http://dsol-smed.phac-aspc.gc.ca/dsol-smed/cancer/> (Version current at August 5, 2008).

16. Health Canada. Canadian Tobacco Use Monitoring Survey (CTUMS): Smoking in Canada - an overview 2003. <http://www. hc-sc.gc.ca/hl-vs/tobac-tabac/research-recherche/stat/ctumsesutc_2003_e.html> (Version current at, July 20, 2007).

17. Health Canada. Health Living: Youth Smoking Survey - 2004 2005. <http://www.hc-sc.gc.ca/hl-vs/tobac-tabac/research- recherche/stat/survey-sondage_2004-2005_e.html> (Version current at May 22, July 2007).

18. Statistics Canada, Projected population by age group according to three projection scenarios for 2006, 2011, 2016, 2021, 2026 and 2031. <http://www40.statcan.ca/101/cst01/demo08a.htm> (Version current at July 15, 2007).

19. Statistics Canada. Portrait of Canadian population in 2006 by age and sex 2006 census. <http://www12.statcan.ca/english/census06/ analysis/agesex/index.cfm>. (Version current at August 20, 2007).

20. Luo J, Adami H, Reilly M, et al. Interpreting trends of pancreatic cancer incidence and mortality: A nation-wide study in Sweden (1960-2003). Cancer Causes Control 2008;19:89-96.

21. Gallicchio L, Kouzis A, Genkinger J, et al. Active cigarette smoking, household passive smoke exposure, and the risk of developing pancreatic cancer. Prev Med 2006;42:200-5.

22. Weiss W, Benarde MA. The temporal relation between cigarette smoking and pancreatic cancer. Am J Public Health 1983;73:1403-4.

23. Sultana A, Smith CT, Cunningham D, Starling H, et al. Metaanalyses of chemotherapy for locally advanced and metastatic pancreatic cancer. J Clin Oncol 2007;25:2607-15.

24. Yip D, Karapetis C, Strickland A, Steer CB, Goldstein D. Chemotherapy and radiotherapy for inoperable advanced pancreatic cancer. Cochrane Database Syst Rev 2006;19;3:CD002093. 


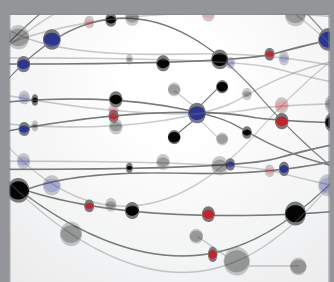

The Scientific World Journal
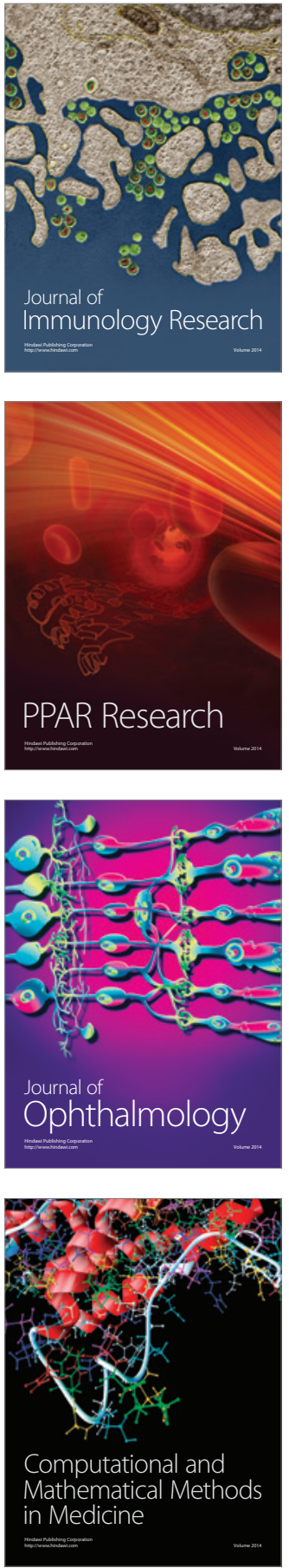

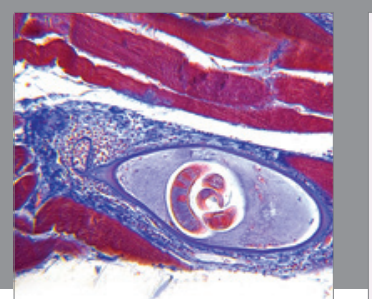

Gastroenterology Research and Practice

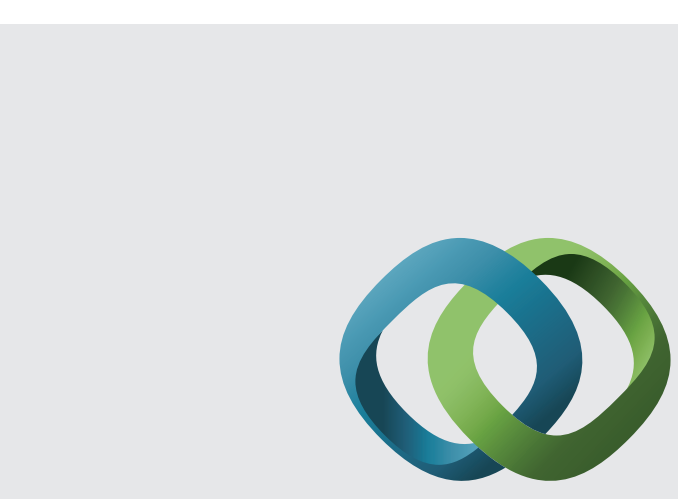

\section{Hindawi}

Submit your manuscripts at

http://www.hindawi.com
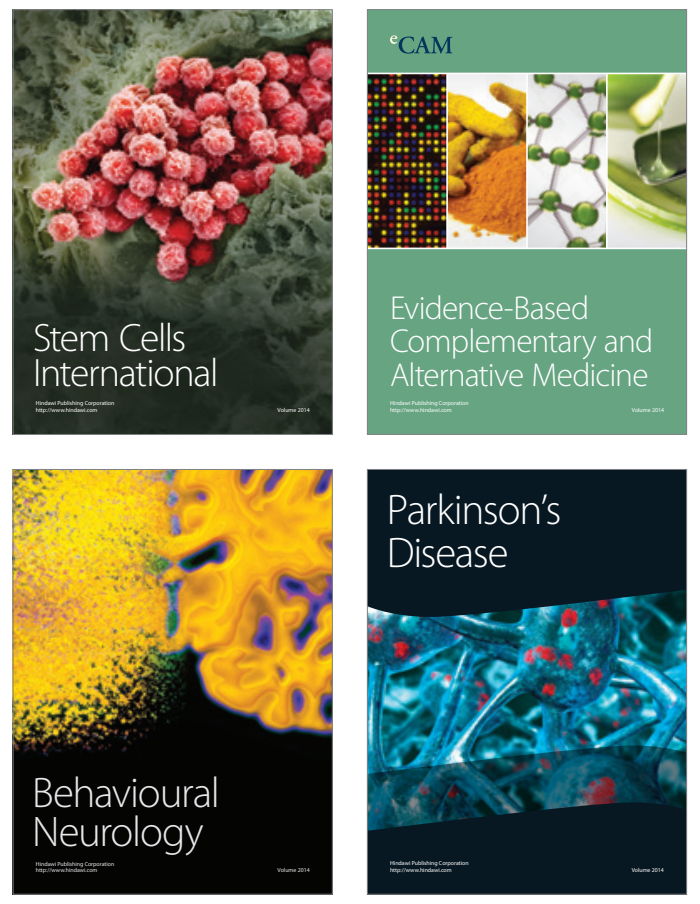
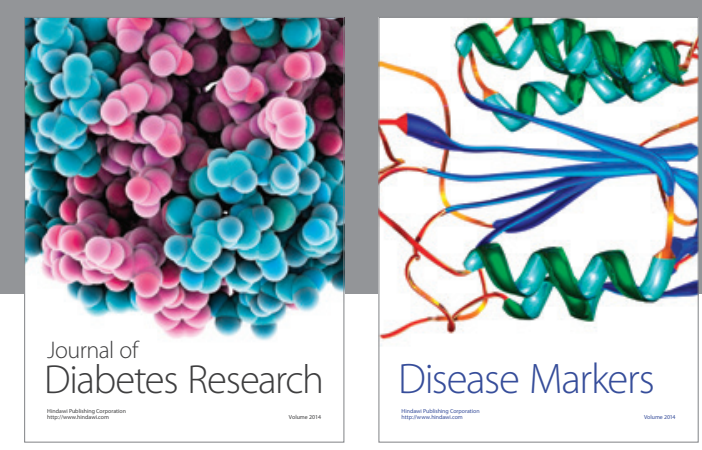

Disease Markers
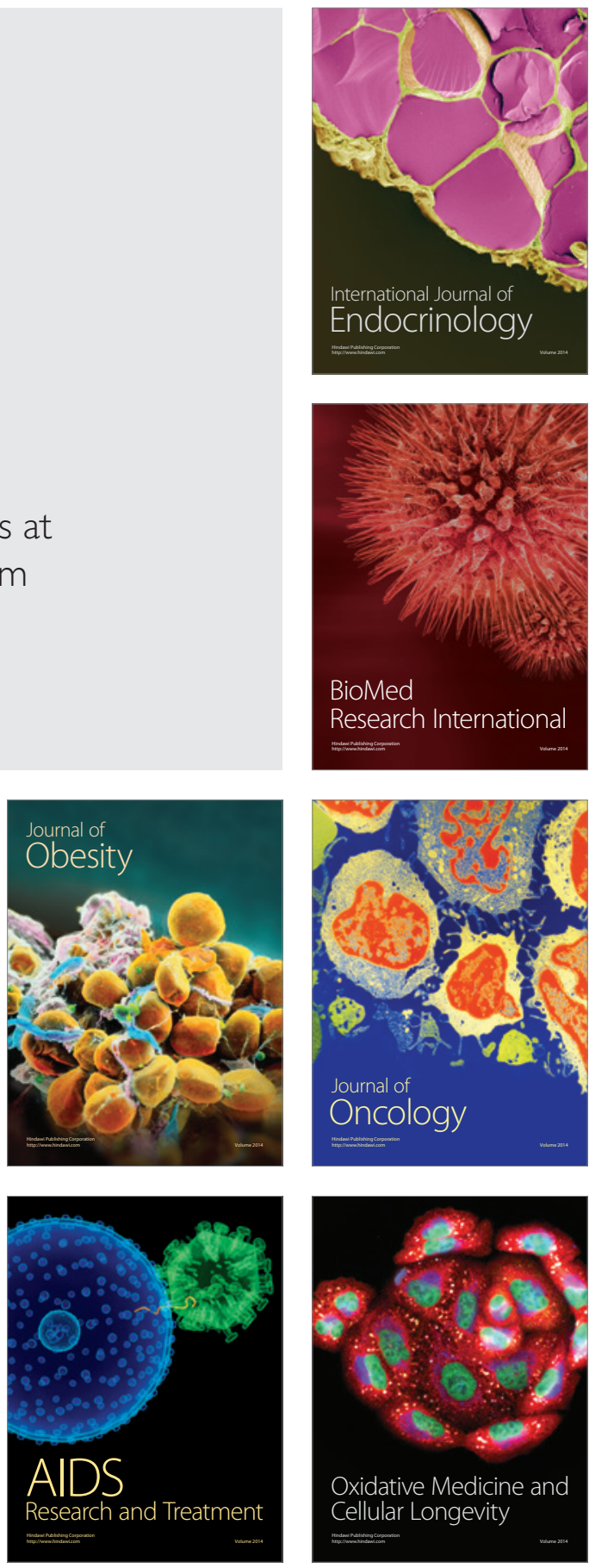